\title{
Determining optimal approaches for weight maintenance: a randomized controlled trial
}

\author{
Kelly S. Dale PhD MSc, Kirsten A. McAuley MBChB PhD, Rachael W. Taylor PhD BSc, \\ Sheila M. Williams DSc BSc, Victoria L. Farmer MSc, Paul Hansen PhD MEc, Sue M. Vorgers RN, \\ Alexandra W. Chisholm MCApSc PhD, Jim I. Mann DM PhD
}

An abridged version of this article appeared in the May 12, 2009, issue of CMAJ

\section{ABSTRACT}

Background: Weight regain often occurs after weight loss in overweight individuals. We aimed to compare the effectiveness of 2 support programs and 2 diets of different macronutrient compositions intended to facilitate long-term weight maintenance.

Methods: Using a $2 \times 2$ factorial design, we randomly assigned 200 women who had lost $5 \%$ or more of their initial body weight to an intensive support program (implemented by nutrition and activity specialists) or to an inexpensive nurse-led program (involving "weigh-ins" and encouragement) that included advice about high-carbohydrate diets or relatively high-monounsaturated-fat diets.

Results: In total, 174 (87\%) participants were followed-up for 2 years. The average weight loss (about $2 \mathrm{~kg}$ ) did not differ between those in the support programs $(0.1 \mathrm{~kg}$, $95 \%$ confidence interval $[\mathrm{CI}]-1.8$ to $1.9, p=0.95)$ or diets $(0.7 \mathrm{~kg}, 95 \% \mathrm{Cl}-1.1$ to $2.4, p=0.46)$. Total and low-density lipoprotein (LDL) cholesterol levels were significantly higher among those on the high-monounsaturated-fat diet (total cholesterol: $0.17 \mathrm{mmol} / \mathrm{L}, 95 \% \mathrm{Cl} 0.01$ to 0.33 ; $p=0.040$; LDL cholesterol: $0.16 \mathrm{mmol} / \mathrm{L}, 95 \% \mathrm{Cl} 0.01$ to $0.31 ; p=0.039)$ than among those on the high-carbohydrate diet. Those on the high-monounsaturated-fat diet also had significantly higher intakes of total fat $(5 \%$ total energy, $95 \% \mathrm{Cl} 3 \%$ to $6 \%, p<0.001)$ and saturated fat ( $2 \%$ total energy, $95 \% \mathrm{Cl} 1 \%$ to $2 \%, p<0.001)$. All of the other clinical and laboratory measures were similar among those in the support programs and diets.

Interpretation: A relatively inexpensive program involving nurse support is as effective as a more resource-intensive program for weight maintenance over a 2-year period. Diets of different macronutrient composition produced comparable beneficial effects in terms of weight loss maintenance. ClinicalTrials.gov trial register no. NCT00128336.

Une version française de ce résumé est disponible à l'adresse www.cmaj.ca/cgi/content/full/180/10/E39/DC1

CMAJ 2009;180(10):E39-E46
$\mathrm{I}$ ncreasing rates of overweight and obesity and the comorbidities associated with excess adiposity have been reported in affluent and developing countries worldwide. ${ }^{1,2}$ Many different dietary and exercise regimens have been shown to be effective in the short term in reducing body weight and improving cardiovascular risk factors and blood glucose in overweight and obese adults..$^{3-8}$ Weight regain typically occurs after intentional weight loss. ${ }^{9}{ }^{90}$ There are relatively few examples in the literature of lifestyle interventions that have produced long-term benefits in terms of maintenance of weight loss, improved risk-factor status or reduced rates of type 2 diabetes, the most immediate comorbidity of obesity. ${ }^{11,12}$ These trials involved intensive and costly interventions.

In the present study, we compared the effectiveness of an intensive program led by health professionals (dietician and exercise specialist) and a more simple, relatively inexpensive nurse-coordinated program for people attempting to maintain weight loss. Additionally, we compared 2 of the most widely recommended nutritional approaches for weight management (high-carbohydrate and high-monounsaturated-fat diets).

\section{Methods}

\section{Participants}

We recruited 200 women aged 25-70 years from a group of 554 volunteers who responded to notices and newspaper advertisements in Dunedin, New Zealand. Volunteers were required to have documented, objective evidence (e.g., records from a general practitioner, dietician or commercial weightloss program) that they had intentionally lost at least $5 \%$ of their initial body weight in the previous 6 months and have or have had a body mass index (BMI) of 27 or greater. We excluded women with chronic physical or psychiatric illness (including diabetes, gestational diabetes, cardiovascular disease,

From the Departments of Human Nutrition (Dale, McAuley, Taylor, Vorgers, Chisholm, Mann), Preventive and Social Medicine (Williams), and Economics (Hansen), University of Otago; and the Edgar National Centre for Diabetes Research (McAuley, Taylor, Farmer, Mann), Dunedin, New Zealand 
renal disease, malabsorption disorders, active treatment for cancer, and conditions that would prevent them from being physically active), those taking medications known to affect weight, those who did not intend to live in the region for 2 years, and those who were pregnant or who intended to conceive within 2 years of recruitment. Each woman gave written consent for participation in the randomized controlled trial.

This trial was approved by the ethics committee of the University of Otago. Trial registration: ClinicalTrials.gov Protocol Registration System, Protocol ID: 03/173, ID: NCT00128336.

\section{Study design and measurements}

We randomly assigned the first 200 women who met the study criteria in blocks of 20 using numbered, opaque sealed envelopes, after stratification based on the extent of their weight loss $(5 \%-7 \%$ or $>7 \%$ of initial body weight) using a $2 \times 2$ factorial design. ${ }^{13}$ Each envelope contained a card that described the nature of the intervention. The participants were assigned to 1 of 4 intervention groups: intensive support and a high-carbohydrate diet; nurse support and a high-carbohydrate diet; intensive support and a high-monounsaturated-fat diet; nurse support and a high-monounsaturated-fat diet. This $2 \times 2$ factorial design permitted comparisons between 100 women in each of the 2 support programs and in each of the 2 diets. The interventions were implemented over a 2-year period (Appendix 1, available at www.cmaj.ca/cgi/content/full/180 /10/E39/DC2). Contamination between the groups was reduced by ensuring that all communal activities were held and measurements made on different days. In accordance with the informed consent form, participants in each group were aware that they had been allocated to groups involving varying levels of support and different types of dietary advice, but they were not provided with details of the alternative program or diets.

Measurements were made at baseline and after 1 and 2 years after randomization, except where specified. For each participant, dietary intake was recorded over a 3-day period, ${ }^{14}$ and hunger and satiety were rated using a 7-point scale before and after the 3 main meals. Participants competed the Profile of Mood States self-administered questionnaire, ${ }^{15}$ International Physical Activity Questionnaire (Long Last 7 Days Self-administered Format for use with young and middleaged adults aged 15-69 years) and the Physical Activity Readiness Questionnaire. The Physical Work Capacity 170 Exercise Test was performed. ${ }^{16}$

At baseline only, participants completed a questionnaire about their weight, dieting history, eating and exercise behaviours. ${ }^{17}$ Two years after randomization, participants completed a program-evaluation questionnaire in which they were asked to comment on the usefulness of the program resources and visits, and the frequency of contacts. Participants also commented on various eating and physical activity behaviours.

Measurements of height (at baseline only), weight, waist circumference, bioelectrical impedance (as a measure of body fat $)^{18}$ and blood pressure were made under standardized conditions. Measurements were duplicated and then averaged. We calculated BMI as weight in kilograms divided by height in metres squared. A blood sample was taken after fasting for measurement of lipids, lipoproteins, glucose and insulin. ${ }^{19}$

\section{Interventions}

Within 2 weeks after randomization, all participants met individually with a nutritionist to receive instruction on their assigned diet. Participants were given a building-block plan based on their diet allocation (including a daily dietary outline to be placed on their refrigerator) and a book of comprehensive dietary information, including colour-illustrated recipes, guidelines for eating out and samples of weekly menus. A week later, participants returned to receive an individualized exercise program from an exercise consultant. The program included type, duration and frequency of exercise with personalized goals. Participants also received a weight chart to track their weight changes.

After 1 year, each participant had a 30 minute consultation with the general practitioner who was participating in the study to discuss anthropometric changes, clinical findings and laboratory tests. Websites were developed during the first year to enable participants to interact with others in the same dietary intervention group without requiring the involvement of the investigators.

During the second year of the study, participants were invited to attend 3 optional group sessions: progressive muscle relaxation and yoga sessions, supermarket tours and dietspecific cooking demonstrations. The interventions differed in the intensity (and cost) of the measures provided to implement the weight maintenance program and the macronutrient composition of the diets.

\section{Support programs}

In addition to the interventions received by all participants, participants in the nurse-support program received weighin visits (5-10 minutes) with the research nurse every 2 weeks for the duration of the study. Participants could briefly discuss their eating and exercise progress. Weight was recorded on participants' individual weight charts. On the alternate weeks, participants received a phone call (about 10 minutes) from the same nurse to discuss their progress. Support groups (1 hour) were provided monthly for each of the diet groups. Discussion topics included a range of eating- and exercise-related topics and coping strategies (e.g., how to read food labels, coping with the holiday season). Each of the participants in the nursesupport program was paired with a "buddy" (support person) who was in the same diet group and whose role was to provide additional encouragement.

The intensive-support program was based on the program used in the Finnish Diabetes Prevention Study. ${ }^{11}$ The support program involved 11 individualized one-on-one sessions (about 35 minutes) with a nutritionist and exercise trainer at 2 and 6 weeks and 3, 4, 6, 9, 12, 15, 18, 21 and 24 months. The sessions covered a variety of nutrition and physical activity topics. Participants were encouraged to attend at least 2 supervised circuit-type resistance-training sessions at a private gym each week for the duration of the study, with each session costing the participant $\$ 2$ (New Zealand dollars). The circuit classes combined high-repetition, low-resistance weight-based training, cardiovascular training and moderate intensity aerobics. 


\section{Dietary intervention}

The high-carbohydrate diet was intended to provide 55\% total energy from carbohydrates, $15 \%-20 \%$ from protein and $25 \%-30 \%$ from fat. Participants were encouraged to consume predominantly low-glycemic index foods (e.g., multigrain breads, legumes, oat cereals, basmati rice) and plenty of fruit and vegetables, and to have moderate intakes of lowfat dairy products, white fish, seafood, lean poultry and lean red meat.

The high-monounsaturated-fat diet was intended to include $25 \%$ total energy from protein, $21 \%$ from monounsaturated fat and $40 \%$ from carbohydrates. Participants on this diet were encouraged to consume plenty of fruit and vegetables and to have moderate intakes of nuts, avocado, and olive and canola oils. They were encouraged to consume low-fat dairy products, white fish, seafood, lean poultry and lean red meat and modest amounts of carbohydrate-containing foods, including pasta, rice and cereals. Both diets were designed to have the same intakes of dietary fibre (30 g/day), saturated fat (8\% total energy) and polyunsaturated fat (6\% total energy). The diets were individually prescribed and based on the food preferences of the participant and her family.

\section{Personnel}

The same senior registered nurse, experienced research dietician, nutritionist and exercise trainer provided the intervention advice throughout the study, made the clinical measurements (having had formal training in anthropometry) and took the blood samples. Although it was clearly not possible for the personnel to be masked as to group allocation, the research assistants and laboratory technicians responsible for analysis of diet records and blood samples were unaware of the program and diet groups.

\section{Statistical analysis}

Power calculations that allowed for outcomes measured on 2 occasions were based on our earlier studies. ${ }^{20}$ After accounting for baseline measures, the standard deviation (SD) of weight was estimated to be $5 \mathrm{~kg}$. Our calculations showed that 100 women per group would be required to detect a $2-\mathrm{kg}$ difference in weight between 2 treatments with $80 \%$ power at a 5\% level of significance, allowing for $20 \%$ of participants to drop out. We assumed that the effects of the support programs and diets were additive. This sample size allowed for the detection of meaningful differences in secondary out-

Table 1: Baseline characteristics of participants in the randomized controlled trial of approaches for weight maintenance

\begin{tabular}{|c|c|c|c|c|}
\hline \multirow[b]{2}{*}{ Characteristic } & \multicolumn{2}{|c|}{ Support program; mean (SD)* } & \multicolumn{2}{|c|}{ Diet group; mean (SD)* } \\
\hline & $\begin{array}{c}\text { Intensive } \\
n=100\end{array}$ & $\begin{array}{c}\text { Nurse } \\
n=100\end{array}$ & $\begin{array}{c}\text { High- } \\
\text { monounsaturated-fat } \\
\text { diet } \\
n=100\end{array}$ & $\begin{array}{c}\text { High- } \\
\text { carbohydrate } \\
\text { diet } \\
n=100\end{array}$ \\
\hline Age, yr & $46(11)$ & $44(10)$ & $45(10)$ & $45(11)$ \\
\hline \multicolumn{5}{|c|}{ Ethnic background, \% of participants } \\
\hline White & 93 & 89 & 90 & 92 \\
\hline Maori & 5 & 10 & 8 & 7 \\
\hline Other & 2 & 1 & 2 & 1 \\
\hline Previous weight loss, kg & $8.3(5.1)$ & $8.6(4.6)$ & $8.5(4.8)$ & $8.4(4.9)$ \\
\hline Previous weight loss, $\%$ & $8.6(4.5)$ & $9.1(4.5)$ & $8.9(4.7)$ & $8.8(4.2)$ \\
\hline \multicolumn{5}{|c|}{ Weight loss method, $\%$ of participants } \\
\hline Commercial & 17 & 14 & 10 & 21 \\
\hline Health professional & 34 & 44 & 40 & 38 \\
\hline Individual & 49 & 42 & 50 & 41 \\
\hline Weight, kg & $86.6(14.1)$ & $85.1(15.1)$ & $86.2(13.6)$ & $85.5(15.6)$ \\
\hline Body mass index & $32.0 \quad(4.9)$ & $31.6(5.1)$ & 31.9 (4.9) & $31.8 \quad(5.2)$ \\
\hline Waist, cm & $96.3(12.1)$ & $93.3(12.7)$ & $95.5(11.8)$ & $94.0(13.1)$ \\
\hline Fat-free mass, kg & $48.8(7.0)$ & $48.5(6.8)$ & $48.7 \quad(6.4)$ & $48.6(7.4)$ \\
\hline Fat mass, $\mathrm{kg}$ & $37.9(8.5)$ & $36.0(9.2)$ & $36.9(8.1)$ & $37.0(9.6)$ \\
\hline Systolic blood pressure, $\mathrm{mm} \mathrm{Hg}$ & $126(14)$ & $122(15)$ & $124(14)$ & $124(15)$ \\
\hline Diastolic blood pressure, $\mathrm{mm} \mathrm{Hg}$ & $80(8)$ & 77 (9) & 78 (9) & 79 (9) \\
\hline Total cholesterol, $\mathrm{mmol} / \mathrm{L}$ & $5.0(1.0)$ & $5.2(1.0)$ & $5.1(1.0)$ & $5.1(1.0)$ \\
\hline HDL cholesterol, $\mathrm{mmol} / \mathrm{L}$ & $1.3(0.3)$ & $1.3(0.3)$ & $1.3(0.3)$ & $1.3(0.3)$ \\
\hline LDL cholesterol, $\mathrm{mmol} / \mathrm{L}$ & $3.4(0.8)$ & $3.2(0.9)$ & $3.4(0.9)$ & $3.3(0.9)$ \\
\hline Triglycerides, $\mathrm{mmol} / \mathrm{L}$ & $1.2(0.5)$ & $1.2(0.7)$ & $1.2(0.6)$ & $1.2(0.6)$ \\
\hline Glucose, $\mathrm{mmol} / \mathrm{L}$ & $4.8(0.5)$ & $4.8(0.5)$ & $4.8(0.5)$ & $4.8(0.5)$ \\
\hline Insulin, mIU/L & $9.1(5.4)$ & $9.4(8.2)$ & $9.4(7.9)$ & $9.1(5.9)$ \\
\hline
\end{tabular}

Note: $\mathrm{Cl}$ = confidence, $\mathrm{HDL}$ = high-density lipoprotein, $\mathrm{LDL}=$ low-density lipoprotein, $\mathrm{SD}$ = standard deviation.

*Unless stated otherwise. 
comes, which included BMI, waist circumference, fat mass, blood pressure, lipids, glucose and insulin levels. Subgroup analyses were not prespecified.

The data were analyzed according to intention to treat, after imputing the missing values by use of chained equations. We used mixed models with participant as a random effect to analyze the main outcome measure (weight) collected at 1 and 2 years, because this type of model accounts for the underlying covariance between repeated measures. The baseline measures were included as covariates. ${ }^{21}$ The preliminary models included terms for the support programs, dietary interventions and time, as well as interactions between support and diet, support and time, and diet and time. Because the interaction effects were not statistically significant, they were not included in the final model that estimated the effect of both interventions. Mixed models were also used for the secondary outcomes. The results are presented as mean and SD for each treatment at each time. A log transformation was used for fasting insulin to stabilize the variances and the results are presented as ratios and $95 \%$ confidence intervals (CIs). A $p$ value of 0.05 or less was considered statistically significant. We did not adjust for multiple comparisons.

\section{Results}

Screening and recruitment took place from April 2004 to October 2004. Baseline characteristics, including weight loss in the 6 months before recruitment were similar in each of the 4 intervention groups (Table 1). Of the 200 participants, 180 (90\%) were followed-up at 1 year and $174(87 \%)$ at 2 years (Figure 1). Anthropometric and body composition measures and lipid, glucose and insulin levels at baseline did not differ in those who were lost to follow-up and those who remained in the trial for 2 years (data not shown).

\section{Support programs}

Participants randomly assigned to both support programs reduced their weight, fat mass, BMI, waist circumference, systolic blood pressure, and levels of glucose and insulin. Lipid levels remained relatively unchanged over the 2 years of the trial (Table 2).

There was little change in the reported physical activity and scores on the Profile of Mood State questionnaire during the course of the trial. There was no significant difference in the results of the Physical Work Capacity test between par-

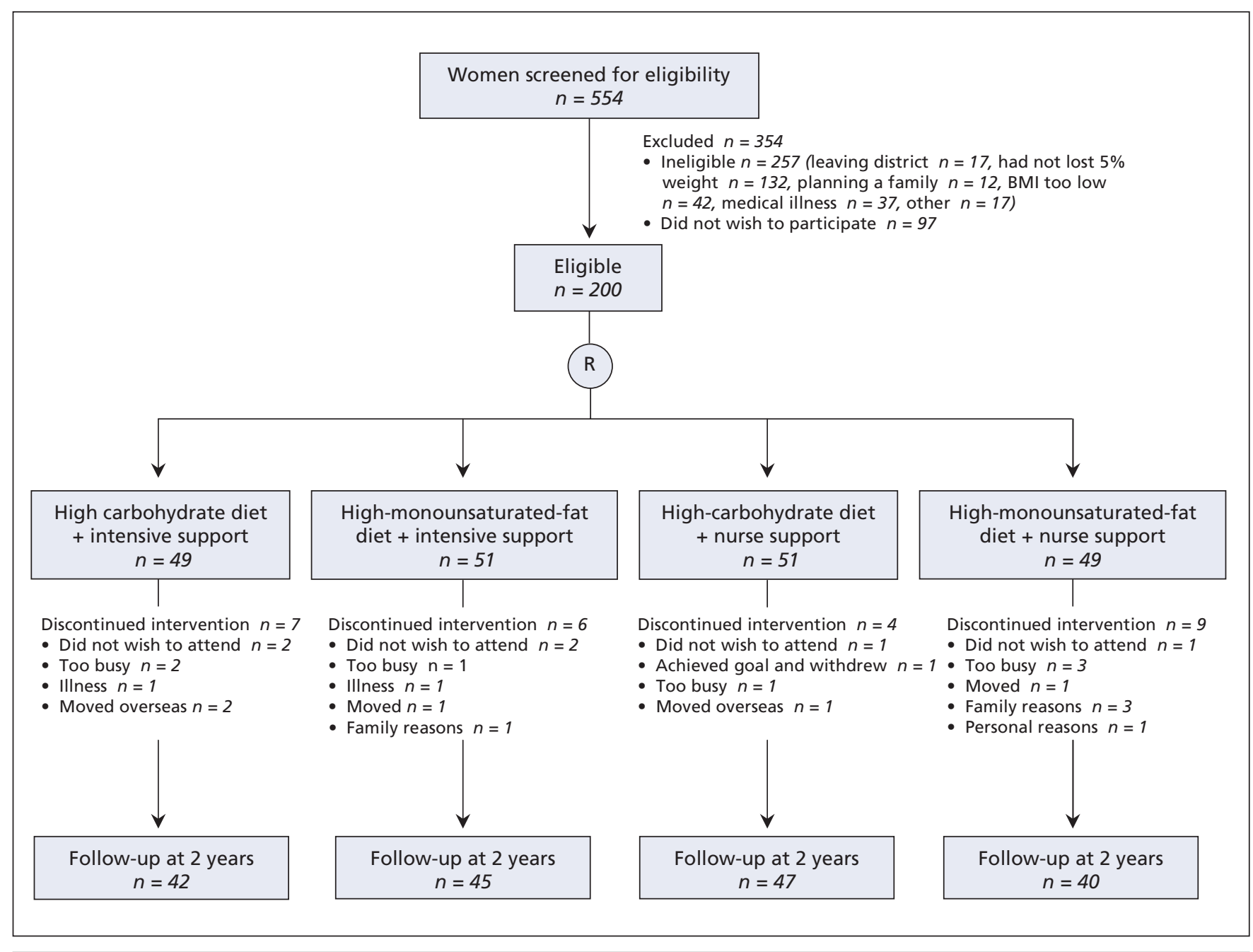

Figure 1: Flow of participants through the trial. 
ticipants in the 2 groups (ratio for the difference between support programs $1.0,95 \%$ CI 1.0 to $1.1, p=0.89$ ).

All of the participants attended the initial discussions during which they were given individualized dietary and exercises advice. Of those in the intensive-support program, 93\% attended all of the sessions with the nutritionist and exercise trainer in the first year, and $87 \%$ attended all of the sessions in the second year. Circuit classes were poorly attended (47\% and $28 \%$ of participants attended on a regular basis in the first and second years, respectively). Of those in the nurse-support program, $89 \%$ attended the weigh-ins in the first year and $85 \%$ attended in the second year. Fewer participants in this group regularly participated in the phone calls $(67 \%$ in the first year, and $65 \%$ in the second year) and attended the support groups on a regular basis (24\% in the first year, and $21 \%$ in the second year). At 2 years, $54 \%$ of participants in the

Table 2: Differences at follow-up in characteristics of participants in the intensive-support program and nurse-support program

\begin{tabular}{|c|c|c|c|c|c|c|}
\hline \multirow[b]{2}{*}{ Characteristic } & \multicolumn{2}{|c|}{ Year 1; mean (SD) } & \multicolumn{2}{|c|}{ Year 2; mean (SD) } & \multirow[b]{2}{*}{ Difference $(95 \% \mathrm{Cl})$} & \multirow[b]{2}{*}{$p$ value } \\
\hline & $\begin{array}{c}\text { Intensive } \\
n=100\end{array}$ & $\begin{array}{c}\text { Nurse } \\
n=100\end{array}$ & $\begin{array}{c}\text { Intensive } \\
n=100\end{array}$ & $\begin{array}{c}\text { Nurse } \\
n=100\end{array}$ & & \\
\hline Weight, kg & $85.0(14.8)$ & $83.3(15.9)$ & $84.3(14.4)$ & $83.0(15.2)$ & $0.1 \quad(-1.8$ to 1.9$)$ & 0.95 \\
\hline Body mass index & $31.5(5.2)$ & $30.9 \quad(5.5)$ & $31.2 \quad(5.1)$ & $30.8 \quad(5.1)$ & $(-0.7$ to 0.7$)$ & 0.95 \\
\hline Waist, cm & $93.3(12.6)$ & $90.9(12.8)$ & $91.6(12.2)$ & $90.1(12.2)$ & $(-2.4$ to 1.4$)$ & 0.61 \\
\hline Fat mass, kg & $36.9(9.8)$ & $34.6(10.4)$ & $36.6 \quad(9.8)$ & $34.6 \quad(9.6)$ & $0.3 \quad(-1.2$ to 1.8$)$ & 0.68 \\
\hline Systolic blood pressure, $\mathrm{mm} \mathrm{Hg}$ & $120(14)$ & $117(12)$ & $123(14)$ & $118(14)$ & $1.5 \quad(-1.4$ to 4.3$)$ & 0.31 \\
\hline Diastolic blood pressure, $\mathrm{mm} \mathrm{Hg}$ & 75 (8) & 74 (7) & $78 \quad(8)$ & 75 (8) & $(-0.9$ to 2.1$)$ & 0.45 \\
\hline Total cholesterol, mmol/L & $5.06(0.92)$ & $4.84 \quad(0.93)$ & $5.09 \quad(0.98)$ & $5.01(0.91)$ & $-0.02 \quad(-0.18$ to 0.15$)$ & 0.86 \\
\hline HDL cholesterol, mmol/L & $1.27(0.35)$ & $1.31 \quad(0.34)$ & $1.27 \quad(0.38)$ & $1.29(0.35)$ & $-0.04 \quad(-0.10$ to 0.01$)$ & 0.13 \\
\hline Triglycerides, mmol/L & $1.09(0.57)$ & $1.11(0.61)$ & $1.14(0.60)$ & $1.08(0.63)$ & $0.01 \quad(-0.09$ to 0.11$)$ & 0.80 \\
\hline Glucose, $\mathrm{mmol} / \mathrm{L}$ & $4.58(0.45)$ & $4.59 \quad(0.51)$ & $4.61 \quad(0.49)$ & $4.54(0.49)$ & $0.05 \quad(-0.04$ to 0.15$)$ & 0.29 \\
\hline Insulin, mIU/L & $7.74(4.55)$ & $7.23 \quad(4.06)$ & $7.07 \quad(5.68)$ & $6.59(5.31)$ & $1.03^{*}(0.92$ to $1.17 *)$ & 0.60 \\
\hline
\end{tabular}

Note: $\mathrm{Cl}=$ confidence interval, $\mathrm{LDL}=$ low-density lipoproteins, $\mathrm{HDL}=$ high-density lipoproteins, SD = standard deviation.

*Ratio of the intensive-support program to the nurse-support program (based on log transformation data).

Table 3: Differences at follow-up among participants in the high-monounsaturated-fat diet group and the high-carbohydrate diet group

\begin{tabular}{|c|c|c|c|c|c|c|}
\hline \multirow[b]{2}{*}{ Characteristic } & \multicolumn{2}{|c|}{ Year 1; mean (SD) } & \multicolumn{2}{|c|}{ Year 2; mean (SD) } & \multirow[b]{2}{*}{ Difference $(95 \% \mathrm{Cl})$} & \multirow[b]{2}{*}{$p$ value } \\
\hline & $\begin{array}{c}\text { High- } \\
\text { monounsaturated- } \\
\text { fat diet } \\
n=100\end{array}$ & $\begin{array}{c}\text { High- } \\
\text { carbohydrate } \\
\text { diet } \\
n=100\end{array}$ & $\begin{array}{c}\text { High- } \\
\text { monounsaturated- } \\
\text { fat diet } \\
n=100\end{array}$ & $\begin{array}{c}\text { High- } \\
\text { carbohydrate } \\
\text { diet } \\
n=100\end{array}$ & & \\
\hline Weight, kg & $84.8(14.7)$ & $83.5(15.9)$ & $84.3(14.3)$ & $83.0(15.2)$ & $0.7 \quad(-1.1$ to 2.4$)$ & 0.46 \\
\hline Body mass index & $31.4 \quad(5.3)$ & $31.0 \quad(5.4)$ & $31.2 \quad(5.1)$ & $30.8 \quad(5.1)$ & $0.2 \quad(-0.4$ to 0.9$)$ & 0.51 \\
\hline Waist, cm & $93.0(12.3)$ & $91.3(13.1)$ & $91.4(11.7)$ & $90.3(12.5)$ & $0.3 \quad(-1.5$ to 2.1$)$ & 0.77 \\
\hline Fat free mass, $\mathrm{kg}$ & $48.6 \quad(7.1)$ & $48.0 \quad(7.3)$ & $48.2 \quad(6.9)$ & $47.7 \quad(7.4)$ & $0.4 \quad(-0.3$ to 1.1$)$ & 0.31 \\
\hline Fat mass, kg & $36.0 \quad(9.9)$ & $35.5(10.5)$ & $35.8 \quad(9.3)$ & $35.4 \quad(9.9)$ & $(-0.9$ to 2.0$)$ & 0.47 \\
\hline $\begin{array}{l}\text { Systolic blood pressure, } \\
\mathrm{mm} \mathrm{Hg}\end{array}$ & $119(12)$ & $118(14)$ & $121(14)$ & $120(14)$ & $0.4 \quad(-2.2$ to 3.0$)$ & 0.75 \\
\hline $\begin{array}{l}\text { Diastolic blood pressure, } \\
\mathrm{mm} \mathrm{Hg}\end{array}$ & $75(7)$ & $75(8)$ & $76(8)$ & 76 (8) & $0.4 \quad(-1.0$ to 1.9$)$ & 0.56 \\
\hline Total cholesterol, $\mathrm{mmol} / \mathrm{L}$ & $5.08(0.96)$ & $4.82(0.87)$ & $5.12(0.93)$ & $4.98(0.93)$ & $0.17 \quad(0.01$ to 0.33$)$ & 0.04 \\
\hline HDL cholesterol, mmol/L & $1.30(0.33)$ & $1.28(0.36)$ & $1.27(0.37)$ & $1.29(0.36)$ & $0.01 \quad(-0.04$ to 0.06$)$ & 0.66 \\
\hline LDL cholesterol, $\mathrm{mmol} / \mathrm{L}$ & $3.27(0.87)$ & $3.04(0.77)$ & $3.34(0.88)$ & $3.18(0.81)$ & $0.16 \quad(0.01$ to 0.31$)$ & 0.039 \\
\hline Triglycerides, mmol/L & $1.11(0.59)$ & $1.10(0.58)$ & $1.11(0.61)$ & $1.11(0.62)$ & $0.00 \quad(-0.09$ to 0.09$)$ & 0.98 \\
\hline Glucose, $\mathrm{mmol} / \mathrm{L}$ & $4.58(0.46)$ & $4.58(0.49)$ & $4.53(0.52)$ & $4.62(0.44)$ & $-0.06 \quad(-0.14$ to 0.03$)$ & 0.21 \\
\hline Insulin, mIU/L & $7.65(4.15)$ & $7.32(4.41)$ & $6.41(5.16)$ & $7.24(5.61)$ & $0.97 *$ (0.87 to $1.09 *)$ & 0.62 \\
\hline
\end{tabular}

Note: $\mathrm{Cl}=$ confidence interval, $\mathrm{HDL}=$ high-density lipoprotein, $\mathrm{LDL}=$ low-density lipoprotein, $\mathrm{SD}=$ standard deviation.

*Ratio of the high-monounsaturated-fat diet to the high-carbohydrate diet (based on log transformation data). 
intensive-support program and $84 \%$ in the nurse-support program found the frequency of their visits appropriate in helping them manage their weight (difference between support programs $\left.\chi^{2}=18.15, p<0.001\right)$. At 2 years, about $70 \%$ of women in both programs reported they would welcome indefinite continuation of the support that they had received during the trial.

\section{Dietary intervention}

Over 2 years, participants assigned to both diets had reduced weight, BMI, waist circumference, fat mass and systolic blood pressure, with no significant differences between the 2 diets (Table 1, Table 3). During the course of the trial, total and low-density lipoprotein (LDL) cholesterol were significantly lower among participants in the high-carbohydrate group than among those in the high-monounsaturated-fat group. Participants' insulin and glucose levels decreased during the study, but there were no significant differences between the diets. There were no differences between the diets for any of the physical activity variables or the scores on the Profile of Mood State questionnaire (data not shown).

Participants in both groups had reduced energy intake after the first and second years of the study relative to baseline intake (Table 4, Table 5). During the follow-up period, those in the high-monounsaturated-fat group had significantly lower intake of energy, carbohydrate and dietary fibre than those in the high-carbohydrate group, but they had higher intakes of protein, total, saturated, monounsaturated and polyunsaturated fat. The participants' hunger and satiety

Table 4: Nutrient intake at baseline among participants on the highmonounsaturated-fat diet and the high-carbohydrate diet

\begin{tabular}{|c|c|c|c|c|}
\hline \multirow{2}{*}{$\begin{array}{l}\text { Nutrient } \\
\text { Energy, kJ }\end{array}$} & \multicolumn{2}{|c|}{$\begin{array}{l}\text { High-monounsaturated- } \\
\text { fat diet, mean (SD) } \\
\qquad n=100\end{array}$} & \multicolumn{2}{|c|}{$\begin{array}{c}\text { High-carbohydrate diet, } \\
\text { mean (SD) } \\
n=100\end{array}$} \\
\hline & 7953 & 883) & 7595 & 2188) \\
\hline \multicolumn{5}{|l|}{ Carbohydrate } \\
\hline Total, $\mathrm{g}$ & 203 & (68) & 220 & (69) \\
\hline$\%$ of total energy & 42 & (10) & 47 & (8) \\
\hline \multicolumn{5}{|l|}{ Protein } \\
\hline Total, g & 94 & (36) & 83 & $(25)$ \\
\hline$\%$ of total energy & 21 & (5) & 19 & (4) \\
\hline \multicolumn{5}{|l|}{ Fat } \\
\hline Total, $\mathrm{g}$ & 73 & (48) & 62 & (26) \\
\hline$\%$ of total energy & 32 & (10) & 30 & (7) \\
\hline \multicolumn{5}{|l|}{ Fatty acids } \\
\hline Saturated, g & 28 & (18) & 25 & $(12)$ \\
\hline Saturated, $\%$ of total energy & 13 & (4) & 12 & (3) \\
\hline Monounsaturated, $\mathrm{g}$ & 27 & $(22)$ & 21 & $(10)$ \\
\hline $\begin{array}{l}\text { Monounsaturated, } \% \text { of total } \\
\text { energy }\end{array}$ & 12 & (5) & 10 & (3) \\
\hline Polyunsaturated, g & 11 & (8) & 9 & (5) \\
\hline $\begin{array}{l}\text { Polyunsaturated, } \% \text { of total } \\
\text { energy }\end{array}$ & 5 & (2) & 5 & (2) \\
\hline Total fibre, $g$ & 22 & (8) & 23 & (7) \\
\hline
\end{tabular}

Note: SD = standard deviation. scores were unchanged during the study for both diets, and there was no significant differences between the groups during the trial.

\section{Interpretation}

Regain of weight is a common occurrence for overweight and obese individuals after short-term weight loss achieved by use of a variety of conventional and alternative weight-loss regimens. In this randomized controlled trial, we have shown that women who are sufficiently motivated to join a 2-year study can maintain their weight and, in many instances, further reduce their weight, waist circumference and body fat mass with a simple, inexpensive nurse-support program. The results were similar for the more costly intensive-support program, which included supervision by several different health professionals. Furthermore, those following a conventional high-carbohydrate, high-fibre diet achieved similar results to those on a lower-carbohydrate diet that was relatively high in monounsaturated fatty acids.

The intensive-support program used in this study was based on the Finnish Diabetes Prevention Study, ${ }^{11}$ which achieved maintenance of weight loss and reduction of diabetes risk over a prolonged period. Although this and other intensive programs $s^{5,12,22,23}$ have been successful, the costs to implement these programs are considerable and well beyond the means of health budgets in many countries. Thus, our finding that a relatively inexpensive program can produce comparable results is of considerable importance.

Other lifestyle interventions with lowintensity support (e.g., phone calls, Internet contact and mailouts) have had limited success. ${ }^{24-27}$ In the study by Wing and colleagues ${ }^{28}$ weight gain among markedly obese individuals who had lost weight before the study was successfully limited over an 18-month period. Programs with face-toface contact on a regular basis (weekly for 1 month and monthly thereafter) had better results than programs with the same frequency of contact via the Internet (mean weight regain of $2.5 \mathrm{~kg} /$ person v. $4.9 \mathrm{~kg} /$ person, after a pre-intervention mean weight loss of 19.3 $\mathrm{kg}$ ). Participants in the study by Wing and colleagues $^{28}$ differed from those in our study in terms of degree of obesity and amount of initial weight loss. However, it is conceivable that the frequent follow-up in our study, especially with regard to weight and several measures of body fat mass, accounted for the difference in findings between the 2 studies.

Improvements in physical fitness and physical activity did not differ during follow-up in the intensive- and nursesupport programs, confirming that costly counselling about physical activity is not an essential component of a program designed 
to maintain weight-loss. In addition, attendance at circuit classes was poor and declined dramatically in the second year, despite the availability of multiple sessions at minimal cost. In contrast, attendance at the weigh-ins was excellent, and many participants reported that the weigh-ins and the enthusiastic support provided by the nurse on those occasions and on the telephone were key determinants of their success.

Claims have repeatedly been made about the weightreducing potential of "diets" of different macronutrient composition. Several meta-analyses have largely dispelled the myth that any particular distribution of macronutrients confers overall advantages in terms of weight loss. ${ }^{729,30}$ However, there is some evidence to suggest that diets relatively low in total carbohydrate may confer benefits in terms of cardiovascular risk determinants in individuals with metabolic syndrome. ${ }^{4,31-33}$

The results of our study confirm that 2 of the most widely promoted dietary prescriptions for weight loss are equally effective options for individuals attempting to maintain their weight after weight loss. It is also reassuring that further weight loss represents a reduction in body fat and not lean body mass, that central adiposity is reduced, and that several other cardiovascular risk determinants (blood pressure, fasting glucose, triglycerides and insulin) are improved. Total and LDL cholesterol did not change appreciably during the course of the trial. The small, yet statistically significant, increase in total and LDL cholesterol among those on the highmonounsaturated-fat diet relative to among those on the high- carbohydrate diet is probably because, despite specific advice to the contrary, saturated fat intake appeared to increase in parallel with monounsaturated fat. As a result, the intakes of saturated fat and total fat were higher among participants on the high-monounsaturated-fat diet than among those on the high-carbohydrate diet.

\section{Strengths and limitations}

The $2 \times 2$ factorial design used in our study was an efficient means of simultaneously assessing outcomes of the 2 support programs and 2 diet interventions. This design and the high retention rate of participants throughout the trial confirm that the findings can be interpreted with confidence. The inclusion of individuals sufficiently motivated to join a 2-year study may be a limitation to the widespread applicability of the findings. These results clearly do not apply to those who have not contemplated the change necessary to facilitate weight loss and maintenance. Without such motivation, it is highly improbable that anyone is likely to achieve success. Although motivation to maintain weight loss is undoubtedly an essential prerequisite of success, in many other long-term trials of sufficiently motivated individuals, most did not achieve longterm maintenance of weight loss. ${ }^{9}{ }^{10}$ Participants did not achieve their dietary targets, but this is almost inevitable in long-term studies of individuals not living in institutions.

Our results have considerable practical implications. They suggest an approach by which overweight and obese people

Table 5: Differences in nutrient intake among participants on the high-monounsaturated-fat diet and the high-carbohydrate diet after 1 and 2 years

\begin{tabular}{|c|c|c|c|c|c|c|c|c|c|c|c|}
\hline \multirow[b]{2}{*}{ Characteristic } & \multicolumn{4}{|c|}{ Year 1; mean (SD) } & \multicolumn{4}{|c|}{ Year 2; mean (SD) } & \multirow{2}{*}{\multicolumn{2}{|c|}{ Difference $(95 \% \mathrm{Cl})$}} & \multirow[b]{2}{*}{$p$ value } \\
\hline & \multicolumn{2}{|c|}{$\begin{array}{c}\text { High- } \\
\text { monounsaturated- } \\
\text { fat diet } \\
n=100\end{array}$} & \multicolumn{2}{|c|}{$\begin{array}{c}\text { High- } \\
\text { carbohydrate } \\
\text { diet } \\
n=100\end{array}$} & \multicolumn{2}{|c|}{$\begin{array}{c}\text { High- } \\
\text { monounsaturated- } \\
\text { fat diet } \\
n=100\end{array}$} & \multicolumn{2}{|c|}{$\begin{array}{c}\text { High- } \\
\text { carbohydrate } \\
\text { diet } \\
n=100\end{array}$} & & & \\
\hline Energy, kJ & \multicolumn{2}{|c|}{$6513(1701)$} & \multicolumn{2}{|c|}{$6319(1610)$} & \multicolumn{2}{|c|}{6985 (2006) } & \multicolumn{2}{|c|}{$6192(1679)$} & 433 & (87 to 779 ) & 0.014 \\
\hline \multicolumn{12}{|l|}{ Carbohydrate } \\
\hline Total, g & 173 & (54) & 197 & (51) & 185 & (61) & 183 & (59) & -7 & $(-19$ to 4$)$ & 0.22 \\
\hline$\%$ of total energy & 43 & (9) & 50 & (7) & 43 & (8) & 47 & (9) & -5 & $(-7$ to -3$)$ & $<0.001$ \\
\hline \multicolumn{12}{|l|}{ Protein } \\
\hline Total, g & 87 & (24) & 79 & (23) & 88 & (24) & 77 & (22) & 8 & (3 to 13 ) & 0.001 \\
\hline$\%$ of total energy & 23 & (5) & 21 & (4) & 22 & (5) & 22 & (5) & & (0 to 2$)$ & 0.13 \\
\hline \multicolumn{12}{|l|}{ Fat } \\
\hline Total, $\mathrm{g}$ & 54 & (24) & 42 & (21) & 61 & (28) & 46 & (20) & 12 & (8 to 17 ) & $<0.001$ \\
\hline Total, $\%$ of total energy & 30 & (8) & 24 & (7) & 31 & (8) & 27 & (8) & & (3 to 6) & $<0.001$ \\
\hline \multicolumn{12}{|l|}{ Fatty acids } \\
\hline Saturated, $\mathrm{g}$ & 18 & (10) & 15 & (8) & 23 & (12) & 17 & (8) & & (2 to 6$)$ & $<0.001$ \\
\hline Saturated, $\%$ of total energy & 10 & (3) & 8 & (3) & 12 & (4) & 10 & (3) & & (1 to 2 ) & $<0.001$ \\
\hline Monounsaturated, $\mathrm{g}$ & 21 & (9) & 14 & (8) & 22 & (11) & 16 & (8) & & (4 to 7 ) & $<0.001$ \\
\hline $\begin{array}{l}\text { Monounsaturated, } \% \text { of } \\
\text { total energy }\end{array}$ & 12 & (4) & 8 & (3) & 11 & (3) & 9 & (4) & & (2 to 3 ) & $<0.001$ \\
\hline Polyunsaturated, g & 9 & (5) & 8 & (6) & 10 & (5) & 8 & (5) & & (0 to 2$)$ & 0.003 \\
\hline $\begin{array}{l}\text { Polyunsaturated, } \% \text { of total } \\
\text { energy }\end{array}$ & 5 & (2) & 5 & (3) & 5 & (2) & 5 & (2) & & (0 to 1$)$ & 0.009 \\
\hline Total fibre, g & 24 & (8) & 27 & (9) & 23 & (8) & 23 & (8) & & $(-3$ to 0$)$ & 0.06 \\
\hline
\end{tabular}

Note: $\mathrm{Cl}=$ confidence interval, SD = standard deviation. 
who have lost weight may be helped to maintain their weight loss. A nurse-led support program involving regular (weekly or biweekly) weigh-ins could be implemented in any country in which general practice is a cornerstone of the health care system. Nurse-led support programs are appealing because they can be implemented within the existing infrastructure and do not require extensive additional training in nutrition and physical activity. Participants reported that the regular contact and encouragement were the key aspects that helped them to sustain their lifestyle changes. Although initial input from experts in lifestyle change (nutritionists, dieticians and exercise consultants) may be helpful, it appears that their long-term involvement is not essential.

The macronutrient distribution of the diet is not a critical determinant of outcome, though our study compared only 2 of the most widely recommended dietary prescriptions. However, these findings serve as an important reminder of the need to ensure that, if monounsaturated fat is increased, there is not a parallel increase in saturated fat. There is evidence from other studies that a dietary prescription involving increased carbohydrate must be implemented by an increase in appropriate carbohydrate sources (e.g., legumes, nonstarchy vegetables, fruit, whole-grain oats). Failure to do so may result in adverse effects on several predictors of cardiovascular and diabetes risk. ${ }^{34}$

\section{Conclusion}

Given the overwhelming costs associated with the comorbidities of obesity, it is encouraging to note that a nurse-supported program to support the maintenance of weight is effective. Such a program can be implemented at a fraction of the cost of an intensive-support program, which many believe is essential for successful long-term maintenance of weight loss. The next step is to evaluate the approach tested in the primary care setting to determine whether our results can be translated into practice.

\section{This article has been peer reviewed.}

\section{Competing interests: None declared.}

Contributors: Kelly Dale, Jim Mann, Kirsten McAuley, Rachael Taylor, Sheila Williams and Alexandra Chisholm conceived and designed the study and obtained funding. Kelly Dale and Sue Vorgers were primarily responsible for the conduct of the intervention. Sheila Williams and Kelly Dale were responsible for the statistical analysis. Paul Hansen and Kelly Dale were responsible for analysis of the cost-related data. Victoria Farmer assisted with data analysis and administration. Kelly Dale and Jim Mann drafted the manuscript and revised it critically along with all other authors. All of the authors approved the final version submitted for publication.

Funding: This study was funded by the Health Research Council of New Zealand. The authors' work was independent of the funders.

\section{REFERENCES}

1. James PT, Leach R, Kalamara E, et al. The worldwide obesity epidemic. Obes Res 2001;9(Suppl 4):228S-33S

2. Mann JI. Diet and risk of coronary heart disease and type 2 diabetes. Lancet 2002;360:783-9.

3. Miller WC, Koceja DM, Hamilton EJ. A meta-analysis of the past 25 years of weight loss research using diet, exercise or diet plus exercise intervention. Int $J$ Obes Relat Metab Disord 1997;21:941-7.

4. Wien MA, Sabaté JM, Iklé DN, et al. Almonds vs complex carbohydrates in a weight reduction program. Int J Obes Relat Metab Disord 2003;27:1365-72.

5. McAuley KA, Smith KJ, Taylor RW, et al. Long-term effects of popular dietary approaches on weight loss and features of insulin resistance. Int J Obes (Lond) 2006;30:342-9.

6. Brand-Miller JC, Holt SHA, Pawlak DB, et al. Glycemic index and obesity. Am J Clin Nutr 2002; 76:281S-5S

7. Astrup A, Grunwald GK, Melanson EL, et al. The role of low-fat diets in body weight control: a meta-analysis of ad libitum dietary intervention studies. Int $J$ Obes Relat Metab Disord 2000;24:1545-52.

8. Nordmann AJ, Nordmann A, Briel M, et al. Effects of low-carbohydrate vs low-fat diets on weight loss and cardiovascular risk factors: a meta-analysis of randomized controlled trials. Arch Intern Med 2006;166:285-93.

9. Dale KS, Mann JI, McAuley KA, et al. Sustainability of lifestyle changes following an intensive lifestyle intervention in insulin resistant adults: follow-up at 2years. Asia Pac J Clin Nutr 2009;18:114-20.

10. Anderson JW, Vichitbandra S, Qian W, et al. Long-term weight maintenance after an intensive weight-loss program. J Am Coll Nutr 1999;18:620-7.

11. Tuomilehto J, Lindström J, Eriksson JG, et al. Prevention of type 2 diabetes mellitus by changes in lifestyle among subjects with impaired glucose tolerance. $N$ Engl J Med 2001;344:1343-50.

12. Knowler WC, Barrett-Connor E, Fowler SE, et al. Reduction in the incidence of type 2 diabetes with lifestyle intervention or metformin. $N$ Engl J Med 2002;346:393-403.

13. Cochrane WC, Cox GM. Experimental designs. New York (NY): Wiley \& Sons; 1957.

14. Edington J, Thorogood M, Geekie M, et al. Assessment of nutritional intake using dietary records with estimated weights. J Hum Nutr Diet 1989;2:407-14.

15. McNair DM, Lorr M, Droppelman LF. EDITS manual for the profile of mood states. Rev. ed. San Diego (CA): Educational and Industrial Testing Service; 1992.

16. Zwiren LD, Freedson PS, Ward A, et al. Estimation of VO2max: a comparative analysis of five exercise tests. Res Q Exerc Sport 1991;62:73-8.

17. Dale K. Approaches for successful weight management $[\mathrm{PhD}$ thesis]. Dunedin (New Zealand): University of Otago; 2003.

18. Deurenberg P, van der Kooy K, Leenen R, et al. Sex and age specific prediction formulas for estimating body composition from bioelectrical impedance: a crossvalidation study. Int J Obes 1991;15:17-25.

19. McAuley KA, Williams SM, Mann JI, et al. Diagnosing insulin resistance in the general population. Diabetes Care 2001;24:460-4

20. McAuley K, Williams S, Mann J, et al. Intensive lifestyle changes are necessary to improve insulin sensitivity. Diabetes Care 2002;25:445-52.

21. Vickers AJ, Altman DG. Statistics notes: Analysing controlled trials with baseline and follow up measurements. BMJ 2001;323:1123-4.

22. Norris SL, Zhang X, Avenell A, et al. Long-term effectiveness of weight-loss interventions in adults with pre-diabetes: a review. Am J Prev Med 2005;28:126-39.

23. Perri MG, McAllister DA, Gange JJ, et al. Effects of four maintenance programs on the long-term management of obesity. J Consult Clin Psychol 1988;56:529-34.

24. Jeffery RW, Sherwood NE, Brelje K, et al. Mail and phone interventions for weight loss in a managed-care setting: weigh-to-be one-year outcomes. Int J Obes Relat Metab Disord 2003;27:1584-92.

25. Crawford D, Jeffery R.W, French S.A. Can anyone successful control their weight? Findings of a three year community-based study of men and women. Int $J$ Obes Relat Metab Disord 2000;24:1107-10.

26. Harvey-Berino J, Pintauro S, Buzzell P, et al. Does using the Internet facilitate the maintenance of weight loss? Int J Obes Relat Metab Disord 2002;26:1254-60.

27. Teixeira PJ, Going SB, Houtkooper LB, et al. Pretreatment predictors of attrition and successful weight management in women. Int $J$ Obes Relat Metab Disord 2004;28:1124-33.

28. Wing RR, Tate DF, Gorin AA, et al. A self-regulation program for maintenance of weight loss. N Engl J Med 2006;355:1563-71.

29. Anderson JW, Konz EC, Frederich RC, et al. Long-term weight-loss maintenance: a meta-analysis of US studies. Am J Clin Nutr 2001;74:579-84.

30. Garg A. High-monounsaturated-fat diets for patients with diabetes mellitus: a meta-analysis. Am J Clin Nutr 1998;67:577S-82S.

31. Zambon A, Sartore G, Passera D, et al. Effects of hypocaloric dietary treatment enriched in oleic acid on LDL and HDL subclass distribution in mildly obese women. J Intern Med 1999;246:191-201.

32. Colette C, Percheron C, Pares-Herbute N, et al. Exchanging carbohydrates for monounsaturated fats in energy-restricted diets: effects on metabolic profile and other cardiovascular risk factors. Int J Obes Relat Metab Disord 2003;27:648-56.

33. Aude YW, Agatston AS, Lopez-Jimenez F, et al. The national cholesterol education program diet vs a diet lower in carbohydrates and higher in protein and monounsaturated fat: a randomized trial. Arch Intern Med 2004;164:2141-6.

34. Mann JI, De Leeuw I, Hermansen K, et al. Evidence-based nutritional approaches to the treatment and prevention of diabetes mellitus. Nutr Metab Cardiovasc Dis 2004; 14:373-94.

Correspondence to: Prof. Jim I. Mann, Edgar National Centre for Diabetes Research, clo Department of Human Nutrition, PO Box

56, Dunedin 9054, New Zealand; fax +64 3479 7958;

jim.mann@otago.ac.nz. 